\title{
EL PRINCIPIO PROTECTOR EN EL DERECHO PROCESAL DEL TRABAJO
}

\author{
Mario Pasco Cosmópolis
}

Al Derecho procesal del trabajo compete la solución de las controversias y conflictos laborales. Por tal razón, como disciplina jurídica es tributaria de dos vertientes: el Derecho procesal y el Derecho del trabajo.

Sus principios deben corresponder y satisfacer de alguna manera a las dos grandes fuentes: por un lado, en su perspectiva instrumental, deben poseer una base dogmática que justifique su existencia autónoma, no dependiente ni derivada de los derechos procesales ordinarios; por otro, de acuerdo a su finalidad, deben recoger y armonizar los principios que, a su vez, dan soporte sustantivo a los derechos del trabajador.

\section{Los principios del derecho}

Problema arduo es definir lo que son los principios del derecho o, expresado de otra forma, a qué categorías jurídicas podemos atribuirles la calidad de principios.

Según Pla Rodríguez ${ }^{1}$, en su obra magistral dedicada precisamente a éstos, principios son: «Líneas directrices que informan algunas normas e inspiran directa o indirectamente una serie de soluciones por lo que pueden servir para promover y encauzar la aprobación de nuevas normas, orientar la interpretación de las existentes y resolver los casos no previstos».

I Pla Rodriguez, Américo: Los principios del Derecho del trabajo, 2." ed. Depalma, Buenos Aires, 1978, pág. 9. 
En esta definición resalta no sólo lo conceptual sino, en esencia, lo teleológico, la triple función que, según DE $\mathrm{C}_{\mathrm{ASTRO}}{ }^{2}$, cumplen los principios: informadora, en cuanto inspiran al legislador y sirven de fundamento del ordenamiento jurídico; normativa o integrativa, al actuar como fuente supletoria ante el vacío o la laguna legal; e interpretativa, al operar como criterio orientador del juez o del intérprete.

Wagner GigLIo previene acertadamente, sin embargo, contra el riesgo de identificar principios con simples peculiaridades, confusion en la que han incurrido con frecuencia los autores, particularmente en el campo del Derecho procesal del trabajo. A este respecto expresa:

«a) Los principios son necesariamente generales, mientras que las peculiaridades son restringidas, pertenecientes a uno o a pocos preceptos o momentos procesales;

b) Los principios informan orientan o inspiran preceptos legales, por inducción, y pueden extraerse de ellos, por medio de razonamiento deductivo; de las peculiaridades no se extraen principios, ni derivan de ellas normas legales;

c) Los principios dan organicidad a institutos y sistemas procesales; las peculiaridades no, pues agotan su actuación en ámbito estrecho generalmente perteneciente al procedimiento y no al proceso.» ${ }^{3}$.

Son muchos los autores, en efecto, que han erigido a las peculiaridades en principios; algunos con gran concisión, como Jorge ANGULO ${ }^{4}$, quien menciona la publicidad, la oralidad, la inmediatez, la celeridad y la concentración, que son tan sólo caracteres típicos del proceso, mas no categorías dogmáticas; otros, con gran profusión y minuciosidad, como CoQueuo Cos$\mathrm{TA}^{5}$, quien llega a enumerar veintidós. En propiedad, tales características o

2 Citado por Pla: ibid., pág. 11.

3 Giglio, Wagner: «Los procesos laborales: su autonomía científica, dogmática y normativa», en Bases para una ley general de Trabajo, IET-CIAT, Lima, 1984, pág. 368.

4 Angulo, Jorge M.: El Derecho procesal del trabajo en el Perú, Trujillo, 1974, pág. 37.

5 Coqueijo Costa, Carlos: «Principios característicos del Derecho procesal del 
peculiaridades derivan de los principios, los concretan o realizan, sirven de vehículo precisamente para que los principios se hagan realidad. Por ejemplo, la oralidad y la celeridad de alguna manera buscan la protección del trabajador, al que la dilación en la resolución de una controversia puede causarle severos perjuicios; la inmediatez deriva de la búsqueda de la verdad material con prevalencia sobre la verdad formal o aparente del proceso. En ambos casos, el principio — protector y de veracidad, respectivamente- es anterior y superior; los caracteres son su correlato.

Sin embargo, con contadas excepciones, la mayoría de autores ha adoptado similar criterio, según destaca Néstor DE BUEN en su reciente Derecho procesal del trabajo ${ }^{6}$.

\section{Los principios del Derecho procesal del trabajo}

El Derecho procesal del trabajo es, por obvia definición, un derecho instrumental; su finalidad «es la de actuar, en la práctica, haciendo efectivo y real el Derecho sustantivo del trabajo»? ${ }^{7}$. A tal efecto, el proceso debe guardar adecuación a la naturaleza de los derechos que en él se controvierten, y si las controversias y conflictos laborales son intrínsecamente distintos a las controversias comunes, resulta indispensable la existencia de un Derecho procesal que, atento a esa finalidad, resulte adecuado a la naturaleza y caracteres de aquéllos.

Adecuación es, precisamente, para el maestro José Martins Catharino ${ }^{8}$, el principio rector del Derecho procesal del trabajo, del que a su vez deriva los principios específicos de paridad procesal («conceder desigualmente a los desiguales en la medida que se desigualan»: Rui BARBOSA); teleológico, o de finalidad social específica; y de normatividad judicial.

trabajo», Derecho Laboral (Montevideo), n. 117 (enero-marzo 1980), págs. 152154.

- Buen, Néstor de, Derecho procesal del trabajo, Porrúa, México, 1988, págs. 72 y ss.

7 Giglio, Wagner: «Los procesos...», ob. cit., pág. 374.

8 Martins Catharino, José, en aula magistral durante el primer Curso de Derecho del Trabajo Comparado, Passo Fundo, Brasil, julio de 1985. 
Para Helios Sarthou', los principios esenciales del Derecho procesal del trabajo son el de materialidad de la verdad, el de equiparación subjetiva (en lo probatorio, lo económico y lo subjetivo), y el de protección.

Wagner Giglio ${ }^{10}$ señala los siguientes: principio proteccionista («el carácter tutelar del derecho material del trabajo se transmite y vigoriza también en el derecho procesal del trabajo»); el de despersonalización del empleador; el de simplificación del procedimiento; y como principios ideales, los de ultrapetición y extrapetición y el de colectivización de las acciones individuales.

Por nuestra parte, consideramos que los principios esenciales del Derecho procesal del trabajo son: a) Principio de veracidad, o de prevalencia del fondo sobre la forma; b) Principio protector, o de desigualdad compensatoria; y c) Criterio de conciencia en la exégesis de la prueba y equidad en la resolución.

De los señalados, el presente artículo estará dedicado a examinar el segundo de ellos: el principio protector.

\section{El principio protector}

Pla Rodríguez coloca como el principal de los principios del Derecho del trabajo el principio protector, cuyo fundamento responde al propósito de nivelar desigualdades. Citando a RADBRUCH, anota: «La idea central en que el derecho social se inspira no es la idea de la igualdad entre las personas, sino de la nivelación de las desigualdades que entre ellas existen»; y a CouTuRE: «El procedimiento lógico de corregir las desigualdades es el de crear otras desigualdades ${ }^{11}$.

Aunque los conceptos antes transcritos abordan la cuestión desde su

9 Sarthou, Helios, en aula magistral en el mismo primer Curso de Derecho del Trabajo Comparado.

10 Giglio, Wagner: «Los procesos...», ob. cit., pág. 369 y ss.

11 Pla Rodríguez, Américo: Los principios del Derecho del trabajo, 2." ed., Depalma, Buenos Aires, 1978, pág. 25. 
perspectiva sustantiva, lo dicho es plenamente válido y hasta más apropiado para el Derecho procesal dado que las desigualdades, el desequilibrio, la posición preeminente del empleador frente al trabajador propias de la relación de trabajo, se trasladan a la relación jurídico-procesal, donde adquieren nuevas manifestaciones.

Dentro de las diferencias que se marcan entre la controversia común y la laboral, acaso la más evidente es la múltiple desigualdad jurídica, económica y probatoria que separa a los contendientes en un litigio de trabajo y que hacen de uno —el empleador — la parte fuerte y del otro -el trabajador- la débil.

La corrección procesal de esta situación, esto es, la protección del débil, puede denominarse también «principio de disparidad social» (Trueba Urbina) o «correctivo de la desigualdad social» (Nicolliello) o de «desigualación compensatoria», en tanto que procura eliminar o, al menos, atenuar o disminuir el desequilibrio creando nuevas desigualdades de signo inverso.

\subsection{Las reglas «pro operario»}

El principio protector se plasma en tres reglas: in dubio pro operario, de la norma más favorable y de la condición más beneficiosa, que $\mathrm{Pla}^{12}$ define así:

«a) La regla in dubio pro operario: criterio que debe utilizar el juez o el intérprete para elegir, entre varios sentidos posibles de una norma, aquel que sea más favorable al trabajador.

b) La regla de la norma más favorable: determina que en caso de que haya más de una norma aplicable, deba optarse por aquella que sea más favorable, aunque no sea la que hubiese correspondido según los criterios clásicos sobre jerarquía de las normas.

c) La regla de la condición más beneficiosa: criterio por el cual la aplicación de una nueva norma laboral nunca debe servir para

\footnotetext{
12 Pla: ibid., pág. 40.
} 
disminuir las condiciones más favorables en que pudiera hallarse un trabajador.

De esta exposición surge que son tres reglas distintas, resultantes del mismo principio general, sin que pueda considerarse una regla subordinada o derivada de otra.»

A ellas cabría agregar la de «retroactividad» recogida por la Constitución peruana que, al establecer la irretroactividad genérica de la ley, exceptúa la ley laboral cuando favorece al trabajador (al igual que la ley penal respecto del reo y la tributaria respecto del contribuyente).

\subsubsection{In dubio pro operario}

Siguiendo a Deveali, señala Pla que:

«El reconocimiento del carácter especial del derecho del trabajo importa el rechazo del principio admitido en el derecho privado, según el cual los casos dudosos deben resolverse en favor del deudor (in dubio pro reo). Este principio, que en un primer tiempo fue ampliamente aplicado aun en el campo de las relaciones laborales, por considerárselas como excepciones a los principios del derecho privado, no puede ser ya admitido, una vez que se reconoce la autonomía del derecho del trabajo, se admite su carácter especial y se acepta que su propósito consiste en otorgar un amparo a la parte débil en el contrato de trabajo; parte más débil que, precisamente a consecuencia de su debilidad, se halla en la mayoría de los casos en la situación de parte acreedora. Si el derecho privado acepta el principio del favor pro reo es porque, en la generalidad de las relaciones civiles o comerciales, el deudor es el más débil y necesitado. Pero en las relaciones laborales ocurre exactamente lo contrario, puesto que en la generalidad de los casos el trabajador, cuya situación de debilidad frente al empleador constituye el supuesto básico del derecho laboral, se presenta como acreedor frente a su empleador.» ${ }^{13}$.

13 Pla: ibid., pág. 41. 
$\mathrm{Y}$, con el mismo prestigioso autor italoargentino, precisa que las condiciones para su aplicación son:

«a) Sólo cuando exista una duda sobre el alcance de la norma legal;

b) Siempre que no esté en pugna con la voluntad del legislador.»14.

Cabe destacar que la regla ha sido elevada a nivel constitucional en el Perú; el artículo 57 in fine de la Carta Magna expresa: «En la interpretación o duda sobre el alcance y contenido de cualquier disposición en materia de trabajo, se está a lo que es más favorable para el trabajador».

La redacción pareciera confirmar su aplicación a la duda sobre la norma, no sobre los hechos, lo que coincidiría con parte de la doctrina ${ }^{15}$. Resume magistralmente esta posición Manoel Antonio TeIxeIra Filho ${ }^{16}$, a quien conviene citar in extenso:

«Hay que destacar, primeramente, que el estado de hesitación de la inteligencia, que caracteriza a la duda, es de fuero esencialmente subjetivo, naciendo en el ánimo del intérprete (en este caso, el juzgador). Vale decir, la duda no está en la prueba producida (que muchas veces contiene una definición en pro de uno de los litigantes) y sí en la persona a quien compete apreciar esa misma prueba. $=$ Ahora bien, el presupuesto concreto para la incidencia de ese principio (esto para quienes sustentan que cabe aplicarlo) es la falta o insuficiencia de pruebas. Excepcionalmente podrá concernir a la existencia recíproca de pruebas (ambas partes probaron los hechos recíprocamente alegados). En cualquier caso, por ello, la cuestión deberá ser solucionada a la luz del onus de la prueba... = Decidirse a favor del trabajador

14 Pla: ibid., págs. 42-43.

15 Ver por todos: Vazquez Vialard, Antonio: «La aplicación de la regla “in dubio pro operario" en el proceso laboral (con especial referencia a los hechos)», en Estudios de Derecho del trabajo y de la seguridad social, 1. ed., 1986, t. I, pág. 97.

16 Teixeira Filho, Manoel Antonio: A prova no processo do trabalho, 4. ${ }^{2} \mathrm{ed}$., Ed. Ltr., Sao Paulo, 1988, pág. 106. (Traducción libre del autor.) 
-sólo porque es el trabajador- es una actitud piadosa, de favor, que se resiente de cualquier lastre de juridicidad. Torna frágil a la sentencia, susceptible de virtual reforma por el grado de la jurisdicción superior. = No estamos cayendo en contradicción, respecto de lo que hasta aquí hemos expuesto en defensa de un reconocimiento sistemático en cuanto a la existencia de una desigualdad real entre el trabajador.y el empleador. La compensación de esa desigualdad, en todo caso, debe ser otorgada por leyes procesales adecuadas y no por la persona del juzgador, en base a criterios subjetivos y casuísticos... = Conviene resaltar: o se prueba o no se prueba. Si en determinado caso las pruebas fueran insuficientes (de ambos lados), el resultado del fallo judicial debe ser desfavorable a quien incumbía el "onus probandi"."

Otra corriente de opinión se inclina por una más amplia noción de la regla, esto es, aplicar el criterio favorable «en casos de auténtica duda para valorar el alcance o el significado de una prueba. No para suplir omisiones; pero sí para apreciar adecuadamente el conjunto de los elementos probatorios, teniendo en cuenta las diversas circunstancias del caso» ${ }^{17}$. A tal efecto, señala José Isidro SoMARE ${ }^{18 .}$

«La duda es admisible, en la conciencia del juez, en cuanto a la forma, al modo, a las características como han ocurrido los hechos. Esto es, si la prueba no fue suficiente para llevar al ánimo del juez la certeza de cómo ocurrió una incidencia, de manera tal que duda, puede, entonces, optar por la solución de favor y acoger la petición del trabajador. No se trata de cualquier hipótesis de duda, ni tampoco la simple duda, si más ni más. Sobre el hecho procesado, no se ha traído prueba directa, asertiva, concluyente. Existen indicios y presunciones. La valoración armónica de tales datos sirva para inclinar al juez en favor de una de las soluciones posibles, en cuanto a la existencia del hecho.»

17 Pla: Los principios..., ob. cit., pág. 46. VÁzquez VIALARD («La aplicación de la regla...»,ob. cit., pág. 96) menciona como partícipes de esa tendencia, entre otros, a Amadeo Allocatti, Alipio Silveira, Santiago Rubinstein, Justo López; en sentido contrario, Benito Pérez y Vásquez mismo.

18 Citado por Pla: Los principios..., ob. cit., págs. 46-47. 
Ésta ha sido, por lo demás, la conclusión a que arribó el IV Congreso Iberoamericano de Derecho del Trabajo (Sao Paulo, 1972).

En cuanto al artículo constitucional peruano, ¡curioso caso de duda el que provoca respecto de aquello que el mismo intenta resolver! Si aplicamos dicho artículo a la interpretación de sí mismo, debemos extenderlo a lo que favorezca al trabajador; y ello nos conduce a la interpretación extensiva, sin duda.

\subsubsection{Norma más favorable}

La regla de la norma más favorable se contrae a:

«Un mandato general e imperativo otorgado al Juez del Trabajo para resolver los casos de colisión o conflicto entre dos o más disposiciones legales, reglamentarias, o contractuales, mediante la aplicación de aquella que más favorezca y proteja el interés del trabajador, independientemente de su naturaleza, origen o ubicación jerárquica. Así, la colisión puede surgir entre una norma sustantiva y una norma adjetiva; entre una norma legal y una norma reglamentaria; entre la ley y el contrato; o entre las estipulaciones de un contrato individual y un contrato colectivo de trabajo; pero en cualquier caso el Juez deberá resolver la colisión aplicando la disposición que mayores ventajas o derechos otorga a los trabajadores.» ${ }^{19}$.

La regla no rompe totalmente el principio de jerarquía normativa, que hace primar a la norma de rango superior sobre la subordinada allí donde exista verdadera implicancia o contradicción. Ello puede darse en dos supuestos: si la norma inferior es posterior en el tiempo, cabe la posibilidad de que sea inválida si desvirtúa o desnaturaliza a la de mayor nivel; si es anterior, la nueva norma la deroga, tratándose, en uno y otro caso, de norma imperativa o de orden público.

19 Villasmil, Fernando: Los poderes del juez de trabajo, Maracaibo, 1979, págs. 34-35. 
Debe resaltarse, empero, la necesidad de una insalvable contradicción entre leyes de distinto grado, hipótesis muy rara, casi teórica, en razón del carácter progresivo del Derecho del trabajo que hace del Derecho objetivo la base, el suelo, el mínimo, y que, invirtiendo la pirámide de la jerarquía abstracta, coloca en su vértice la norma más favorable ${ }^{20}$. De acuerdo a ello, la norma menos amplia perfecciona, mejora a las que le anteceden y se aplica por encima de éstas, lo que vale para la ley común frente a la Constitución, para el reglamento frente a la ley, etc.

\subsubsection{Condición más beneficiosa}

Dice PLA ${ }^{21}$ :

«La regla de la condición más beneficiosa supone la existencia de una situación concreta anteriormente reconocida y determina que ella debe ser respetada en la medida que sea más favorable al trabajador que la nueva norma que ha de aplicarse.»

Y agrega, siguiendo a Alonso García, que:

"Opera en dos direcciones: restrictiva, la una, extensiva, en cambio, la otra. Opera restrictivamente, ya que por aplicación de dicho principio las partes se ven forzadas (el empresario, sobre todo) a situaciones más ventajosas para el trabajador que las que éste disfrutaría al aplicarse la nueva resolución. = Opera extensivamente en la medida en que por aplicación del mismo principio, si bien indirectamente, les es posible a las partes establecer condiciones superiores, más beneficiosas que las mínimas fijadas legalmente. ${ }^{22}$.

Las tres reglas son "pro operario», integran un principio protector al trabajador $y$, en la perspectiva de la obra del maestro uruguayo, correspon-

20 Vid. Mascaro Nascimento, Amauri: citado por Pla: Los principios..., ob. cit., pág. 54.

21 Pla: ibid., pág. 60.

22 Pla: ibid., págs. 64-65. 
den al Derecho laboral sustantivo. Nada obsta, empero, para que se apliquen en el Derecho procesal: directamente si, por ejemplo, el juez tuviera dudas sobre el alcance o sentido de una norma adjetiva, caso en el cual deberá aplicarla en la forma que favorezca al trabajador; o si resultaran de aplicación a una misma situación procesal dos normas diferentes, en que deberá optar en igual sentido que el anterior.

Pero es indirectamente como estas reglas tienen presencia más constante en el proceso laboral. En efecto, el proceso es un medio a través del cual actúa y logra plena vigencia y eficacia la norma material, que es su objeto, su razón de ser. La duda, la colisión de dos normas o de una norma y una condición fáctica son problemas procesales; esa duda es la duda del juez; es el juez el que debe optar entre dos leyes contradictorias o hacer prevalecer la condición más benéfica.

El principio protector o pro operario determina reglas que habrán de guiar el comportamiento del juez, orientar, condicionar, conducir su decisión. No obstante su entraña sustancial, son reglas raigalmente procesales; de allí que como principio no es sólo igualmente válido para el derecho laboral y para el procesal del trabajo, sino casi podría decirse que lo es más para éste, porque es en los procesos laborales donde tiene más ancha cabida y más constante aplicación.

Si la duda la tuvieran empresarios o trabajadores, lo más probable es que la resolvieran cada uno por su lado y de acuerdo a sus contrapuestos intereses; así, la vacilación subjetiva de cada cual se convertiría en convicción de cada uno de ser el que tiene la razón, y ésa es normalmente la semilla del litigio. En la relación cotidiana la duda no se resuelve «pro operario»; no se resuelve, sencillamente; se traslada a y se convierte en litigio.

Es la duda del juez, entonces, la que interesa; y es en su dimensión procesal, por tanto, que el principio pro operario se hace tangible. Por eso lo consideramos como principio esencial para el Derecho procesal del trabajo.

\subsubsection{Retroactividad}

Según indicamos líneas arriba, la Constitución peruana consagra como prin- 
cipio general el de irretroactividad de la ley, pero con las tres excepciones siguientes: la ley penal, la tributaria y la laboral, cuando son más favorables al reo, al contribuyente y al trabajador, respectivamente.

La irretroactividad es, entonces, norma, y la retroactividad, excepción. Por ello, el efecto no es instantáneo ni automático: no toda ley laboral es necesariamente retroactiva cuando beneficia al trabajador, sino que tal efecto tiene que serle atribuido de modo expreso. Incluso puede darse esta situación sólo para parte de la ley, como ha sucedido ya en la realidad.

En el campo procesal, concretamente, puede también conferirse carácter retroactivo a la norma: recientemente, por ejemplo ${ }^{23}$, se han variado ciertas reglas relativas a la contratación colectiva, las que por su naturaleza sólo debieran regir a futuro; sin embargo, la propia norma autoriza a los trabajadores para que puedan reformular sus pliegos de peticiones en trámite para adecuarse al nuevo sistema. Como quiera que las convenciones colectivas en el Perú tienen también efecto retroactivo, permitir que los pliegos sean variados después de iniciadas las negociaciones implica dar retroactividad a la norma. Con ello se demuestra que la retroactividad es dable también en el terreno procesal y no sólo en el sustantivo.

\subsection{Iniciación de oficio del proceso}

Es atributo reconocido a la inspección de trabajo (Convenio 81 de la OIT) velar por el cumplimiento de las disposiciones relativas a las condiciones de trabajo y a la protección de los trabajadores en el ejercicio de su profesión.

De esa facultad, que nadie discute, algunas legislaciones, en especial la española, han derivado la posibilidad de que la administración del trabajo, anticipándose y aun sustituyendo la acción personal del trabajador en resguardo de sus derechos conculcados, dé inicio a un proceso judicial mediante la remisión a la magistratura respectiva de copia certificada del acta de infracción o, según el caso, de la resolución firme dictada en lo administrativo.

${ }^{23}$ Decreto supremo n. ${ }^{\circ}$ 058-90-TR, que modifica reglas sobre negociación colectiva. 
Dice al respecto Montoya Melgar ${ }^{24}$ :

«El legislador no se limita a evidenciar la conexión entre cumplimiento del ordenamiento laboral y cumplimiento de los contratos de trabajo, o, en su reverso, entre infracción administrativa e incumplimiento contractual, encomendando a la inspección el cuidado de que los contratos se ajusten a las prevenciones legales, sino que, consciente de la inmediatividad real de los problemas planteados por la infracción / incumplimiento, instrumenta un mecanismo procedimental a través del cual pone en relación la vía administrativa (sancionadora) y la vía jurisdiccional (de atribución de derechos). Ese mecanismo es la llamada "demanda de oficio" para cuya interposición está facultada, como postulante público, la Administración de Trabajo. El fundamento de esta iniciación oficial del proceso de trabajo está suficientemente claro: la Administración de Trabajo, en virtud de su función tuitiva, reconocida por la ley y la jurisprudencia, suple o sustituye la acción del trabajador afectado por un incumplimiento empresarial que simultáneamente sea infracción del Ordenamiento y violación de deber contractual, realizando una actividad procesal equivalente a la demanda, y con la cual quiere prevenirse el perjuicio que se derivaría para el trabajador, bien sea por ignorancia de los derechos, bien por el temor de ejercitarlos.»

La legislación brasileña contempla una situación similar cuando las alegaciones del empleador, en el curso de una inspección, versan sobre la inexistencia de la relación laboral y resulta imposible verificar esa condición por los medios administrativos, caso en el cual el proceso es encaminado a la Justicia del Trabajo (artículo 39 de la CLT). Los actuados administrativos fungen de cabeza del proceso judicial.

Iniciativa ex officio de la acción existe también en la República Argentina, para el caso de los accidentes de trabajo.

24 Montoya Melgar, Alfredo: «Inspección del trabajo y efectividad de los derechos laborales: sobre la iniciación de oficio de los procesos de trabajo», separata de Derecho y Proceso, Murcia, 1980, págs. 561-562. 
Interesa resaltar en este tema dos aspectos: por un lado, la ruptura que este sistema representa del principio procesal civil Nemo Judex sine actore; $y$, por el otro, su motivación, que según Montoya Melgar radica en la «función tuitiva» reconocida a la Administración, que, en este caso, trasciende a lo procedimental.

GIGLIO $^{25}$ anota como principio ideal del Derecho procesal del trabajo, esto es, «revelado o intuido por algunas tendencias actuales, en vías de sedimentación, o sugerido o propuesto por la doctrina para consolidar, en el futuro, el perfeccionamiento del proceso laboral», el que él llama «colectivización de las acciones individuales», según el cual, siendo normal la iniciativa de una acción, vale decir, a instancia de parte, «el propio Poder Judicial, a título de economía procesal, extendería el ámbito personal de la acción para que participasen de ella otros trabajadores que se encontrasen en la misma situación de hecho del actor", una suerte de convocatoria ex officio de litis consortes activos.

Economía procesal, sí, pero también extensión del principio protector, y que se vincula con la facultad del juez de iniciar ciertos procesos por su sola iniciativa; en este caso para pluralizarlos, más que colectivizarlos.

\subsection{Redistribución de la carga de la prueba}

En sentido estricto, al proceso civil deben aplicársele dos principios, que están traducidos en sendos aforismos: «Quien afirma algo está obligado a demostrarlo» y «Si el demandante no prueba, el demandado será absuelto» ${ }^{26}$. De acuerdo a ello, la carga probatoria es siempre del accionante, quien está en la necesidad y en la obligación de acreditar con elementos de convicción que los hechos que alega son ciertos.

25. GigLIO, Wagner: «Los procesos laborales: su autonomía científica, dogmática y normativa», en Bases para una ley general de Trabajo, IET-CIAT, Lima, 1984, págs. 373-374.

26 «Semper onus probandi ei incumbit qui dicit» o «Semper necessitas probandi incumbit illi qui agit» $\mathrm{y}$ «Actor non probante, reus absolvitur», en su expresión latina. 
En el Derecho procesal del trabajo este criterio es deliberadamente quebrantado, subvertido: el trabajador, que es el actor o demandante, es exonerado en lo sustancial de la obligación de probar su dicho; el onus probandi recae básicamente sobre el empleador, el demandado.

La demanda goza, por decirlo así, de una presunción de veracidad, se le reputa cierta a priori, presunción juris tantum que debe ser destruida por el empleador con su prueba.

El principio de «redistribución de la carga de la prueba» no es meramente abstracto o teórico; tiene, por el contrario, constante y contundente presencia en la legislación. La peruana, por ejemplo, lo consagra en sus dos manifestaciones: en el artículo 32 del decreto supremo 03-80-TR, sin descargar totalmente al trabajador de su obligación probatoria, restringe ésta a la sola demostración de la existencia de la relación laboral. Probada ésta, el empleador deberá acreditar, de allí en adelante, que ha cumplido con las disposiciones legales y convencionales respectivas, lo que equivale a tener que probarlo todo, ya que lo que se discute precisamente en un litigio es su presunto incumplimiento. De otro lado, el emplazamiento con la demanda se practica «bajo apercibimiento de tenerse por ciertos los hechos expuestos», aun sin necesidad de prueba, si el empleador no concurriese a la citación o si, concurriendo, no presentara el escrito de contestación (artículo 21).

Asimismo, la sentencia deberá declarar fundada la demanda: i) respecto a los puntos que no hubieran sido expresamente contradichos (allanamiento tácito), y ii) respecto de los puntos en que, correspondiendo la carga de la prueba al demandado, éste no los hubiera probado (artículo 50).

Desde esta perspectiva, entonces, pueden extraerse las reglas siguientes:

a) La demanda se presume verdadera a priori, lo que se traduce en un apercibimiento de tenerse por cierto su contenido si el demandado incumple con el trámite de contestación.

b) La demandą impone contestación específica respecto de cada uno de los extremos que contiene; la falta de contradicción expresa respecto de alguno de ellos implica un allanamiento tácito. 
c) El trabajador sólo tiene obligación formal de probar la existencia de la relación laboral, sin que ello implique impedimento ni exoneración absoluta de demostrar complementariamente los diversos hechos que afirma.

d) Corresponde al empleador probar que no debe, que no ha incumplido o que ya pagó, que es, en esencia, lo nuclear del proceso, pues son su incumplimiento, su débito o su mora lo que se discute como fondo de la controversia.

La de probar es, jurídicamente, una carga, no una obligación, pues en la obligación los efectos del incumplimiento afectan a un tercero, mientras en la carga sólo perjudican al omiso o infractor. Como dice CARNELUTTI ${ }^{27}$ : «La diferencia entre onus y obligación se funda en la sanción diversa a quien no cumple determinado acto; existe obligación cuando la inactividad da lugar a una sanción jurídica (ejecución o pena); si, al contrario, la abstención en relación al acto determinado hace perder solamente los efectos últimos de ese mismo acto, nos encontramos frente a la figura del onus».

En el litigio civil, como en el laboral, ambas partes deben probar lo que afirman; pero el peso de la carga probatoria se distribuye de manera diferente; en el civil, recae sobre el actor; en el laboral, sobre el demandado.

GigLı, fundamentando la reversión probatoria, expresa:

«Además de la diversidad de situación económica y de la desigualdad resultante de la subordinación del trabajador al empleador, otro substracto de hecho lleva a rechazar la adopción de esa doctrina (la doctrina civilista de la igualdad procesal absoluta): mientras los contratantes, en la esfera civil, tienen posibilidades iguales de producir prueba, en el campo laboral es notoria la inferioridad del trabajador, según veremos. = La prueba testimonial debe ser obtenida de otros empleados, que por definición se encuentran subordinados al empleador, lo que cohíbe la libertad de sus declaraciones: no ignoran ellos que si sus declaraciones perjudicaran al patrón, corren el riesgo de perder sus

27 Carnelutti, Francesco, citado por Teixeira Filho: A prova no processo do trabalho, ob. cit., pág. 81 . 
empleos. Si eso no fuera suficiente, la prueba documental, más segura, rara vez puede ser presentada por el trabajador: subordinado a las determinaciones de sus superiores, no tiene medios para exigir comprobantes, en tanto la empresa cuenta con un departamento de personal, toda una organización contable que dispone de abundante documentación. La práctica evidencia que el trabajador desconoce, por regla general, los datos más elementales relativos a las condiciones en que presta servicios: cálculo del salario, monto de los descuentos, número de horas extras, etc. = Urge corregir estos desequilibrios, confiriendo al empleador mayores cargas en la producción de la prueba.» ${ }^{28}$.

La reversión de la carga de la prueba no es, sin embargo, un criterio unánimemente aceptado; hay doctrinarios que la recusan y legislaciones que no la contienen.

En la doctrina española, por ejemplo, Rodríguez Piñeiro y Bravo FERRER $^{29}$ señalaban como principios informadores del proceso laboral el contradictorio y el de aportación de prueba, de los que desprenden la igualdad de ambas partes en el proceso. Montoya Melgar ${ }^{30}$, luego de enfatizar la íntima fusión de lo sustantivo y lo procesal y de calificar al Derecho del trabajo, en esa doble e indisoluble relación, de «ordenamiento compensador e igualador», refleja estos caracteres en diversos principios, mas no en materia probatoria, en la que rige el principio de acusación «según el cual son las propias partes en litigio las que han de aportar al juzgador la alegación de los hechos y la proposición de las pruebas que estimen precisas para fundamentar su derecho (da ruiti factuum et dabo tibi ius) ${ }^{31}$.

28 Giglio, Wagner: Direito processual do trabalho, Ed. LTr, Sao Paulo, 1977, págs. 69-70.

29 Rodríguez Piñeiro, y Bravo Ferrer, Miguel: «Sobre los principios informadores del proceso de trabajo», en El Derecho del trabajo en España, IES, Madrid, 1981, t.I, págs. 729-730.

30 Montoya Melgar, Alfredo: Derecho del trabajo, 8. ed., Tecnos, Madrid, 1987, págs. 690-691.

3 El Tribunal Constitucional español ha sentado nueva doctrina sobre la carga de la prueba en relación con la actividad discriminatoria del empleador en perjuicio del trabajador y de la presunción de inocencia en los casos de despido y sanciones disciplinarias. 
Néstor DE BUEN, con referencia a la legislación mexicana, considera que uno de los principios que la sustentan es la «carga procesal de quien afirma y no del que niega» ${ }^{32}$, aunque destaca favorablemente la facultad concedida a la Junta de Conciliación y Arbitraje de «eximir de la carga de la prueba al trabajador, cuando por otros medios esté en posibilidad de llegar al conocimiento de los hechos», regla a la que califica de «curiosa afectación al principio dispositivo ${ }^{33}$. Citando a Alberto Trueba Urbina, indica que en el Derecho procesal laboral mexicano puede invocarse el principio de igualdad de las partes ${ }^{34}$; y considera «inquietante la desigualdad procesal», una de las «cuestiones que pueden llegar a generar más encono» ${ }^{35}$.

En su opinión, el carácter tuitivo de las normas laborales sólo se da en el derecho individual; en el colectivo «el régimen de huelga y el del contrato colectivo de trabajo han creado el equilibrio»; y «en el derecho procesal del trabajo tampoco existe tendencia proteccionista alguna. La relación procesal contempla a los sujetos con igual criterio, si bien es indiscutible que la distribución de la carga de la prueba y el criterio de resolución "en conciencia", favorecen a los trabajadores» ${ }^{36}$.

No es ésa, ciertamente, la posición de Trueba URBina, uno de los más categóricos sustentadores de la necesidad de un proceso desigual basado en «privilegios compensatorios» en favor de los trabajadores, al punto de sostener que «las pruebas en el proceso laboral no tienen una función jurídica sino social, pues tienen por objeto descubrir la verdad real, no la verdad jurídica», y que «rige el principio de inversión de la carga de la prueba en favor del trabajador ya que el patrón tiene más facilidades y recursos probatorios $»^{37}$.

32 Buen, Néstor de: «Los principios generales del Derecho del trabajo en el ámbito procesal», Derecho Laboral (Montevideo), n. 117 (enero-marzo 1980), pág. 139.

33 Buen, Néstor de: La reforma del proceso laboral, Porrúa, México, 1983, pág. 58.

34 lbid., pág. 24.

35 Ibid., pág. 37.

36 Buen, Néstor de: Derecho del trabajo, 2. a ed., Porrúa, México, 1977, t. I, pág. 60.

37 Trueba Urbina, Alberto: Nuevo Derecho del trabajo, Porrúa, México, 1972, págs. 250-251. 
Interesante posición sustenta Alcione NiEDERAUER CORREA ${ }^{38}$ para reforzar la reversión del onus de la prueba con mayores «deberes de control y de documentación, impuestos al empleador, capaces de constituirse en instrumentos de preconstitución de prueba que, en caso de inexistencia, generarían presunción en favor del trabajador. La forzalización de ciertos actos, la obligatoriedad de prueba documental y de justificación de determinadas manifestaciones de voluntad, limitativas de futuros conflictos judiciales, es el único camino. A través de deberes impuestos al empleador es que cabe la formalización de muchos de los principios, hasta aquí teóricos, de Derecho del Trabajo».

En esa línea, la legislación peruana obliga a registrar en un libro especial denominado "planilla» todos los elementos configurados en la relación de empleo: fecha de ingreso, salario, días trabajados, horas extras, descuentos, etc. La planilla debe consistir en un libro foliado, sellado y rubricado por la Autoridad de Trabajo o en hojas sueltas con iguales requisitos, en el que el empleador debe registrar a todo nuevo trabajador dentro de las veinticuatro horas de su ingreso. El trabajador recibe, conjuntamente con su pago, una boleta en la que deben constar los mismos datos que figuran en la planilla, debiendo firmar un duplicado como comprobante del pago.

Lo importante -además de proveer al trabajador de prueba documental- es que la omisión en llevar la planilla o de registrar en ella a un trabajador o en la firma por éste de la boleta determina, en caso de litigio y si el trabajador prueba la existencia del vínculo laboral, que se deban tener por ciertas sus afirmaciones acerca de los diversos actos que en dicho instrumento formal debieran constar.

BARBAGELATA ${ }^{39}$ hace notar que la nueva LFT mexicana contiene un principio similar respecto de todos los documentos que el empleador tenga obligación de conservar; y que «la mayoría de los textos iberoamericanos hacen recaer en el empleador las consecuencias de la falta de escritura del contrato de trabajo o de sus modalidades, cuando la ley las impone, exclu-

38 Niederauer Correa, Alcione: «Analise critica do processo do trabalho no Brasil», Revista do TRT, Curitiba, vol. V, n. ${ }^{\circ} 1$, pág. 62.

39 Barbagelata, Héctor Hugo: «Los medios de prueba en el procedimiento laboral», Derecho Laboral (Montevideo), n.`119, pág. 545. 
yendo la posibilidad de que sean probadas supuestas cláusulas que resulten perjudiciales para el trabajador» ${ }^{40}$. El artículo 39 del CT de Ecuador dispone, en tal dirección, que «s6́lo el trabajador podrá hacer valer los derechos, y consiguientemente probar por otros medios, incluso por su propio juramento, los derechos emanados de contratos que conforme al artículo $18 \mathrm{del}$ mismo Código hubieran debido celebrarse por escrito" ${ }^{4}$.

GigLio - a nuestro ver, acertadamente- habla de «redistribución» y no de «reversión o inversion» de la carga probatoria, que han sido las expresiones anteriormente más usadas. Revertir o invertir implica trastocar, aplicar a uno lo que corresponde al otro y viceversa. Redistribuir, en cambio, es atribuir de modo diverso, que en eso consiste propiamente este principio cuando hace recaer el peso de la prueba de modo desigual, pero no necesariamente intercambiado entre las partes. El Tribunal Constitucional español utiliza el término «desviación de la carga de la prueba».

\subsection{Otras normas de protección}

Las manifestaciones del principio protector antes reseñadas no son las únicas; son apenas las más importantes. Existen otras, múltiples, que contornan y conforman dicha protección, tales como:

Gratuidad: el proceso laboral es siempre gratuito para el trabajador, quien está exonerado del uso de papel sellado, pago de tasas, costas, etc., que en cambio sí constituyen, por lo general, obligación para el empleador.

Defensa gratuita: en la generalidad de los países, el trabajador puede obtener patrocinio letrado gratuito a través de órganos que, en algunos casos, dependen de los servicios del Ministerio de Trabajo, y en otros constituyen institutos independientes (Procuraduría del Trabajo).

Oralidad-concentración-inmediación-celeridad: este conjunto de atributos, íntimamente ligados entre sí y virtualmente inseparables, debe condu-

\footnotetext{
$40 \quad$ lbid., pág. 549.

4 I Ibid., pág. 549.
} 
cir a un proceso ideal en el que el máximo de actos pueda ser cumplido en un mínimo de diligencias, presididas personalmente por el propio juez y ejecutadas en forma prevalentemente oral, en aras de lograr una resolución no sólo justa y equilibrada, sino pronta, habida cuenta de la naturaleza alimentaria de los derechos patrimoniales del trabajador y la urgencia social que unánimemente se les reconoce.

Es a estos caracteres típicos o peculiaridades, derivados e integrantes del principio protector, a los que gran número de estudiosos han tomado por principios, sin advertir que son efecto y no causa. 